\title{
PENENTUAN KANDUNGAN RESIDU PESTISIDA DALAM TEH KOMERSIAL DI INDONESIA MENGGUNAKAN KROMATOGRAFI GAS DENGAN DETEKTOR PENANGKAP ELEKTRON
}

\section{Determination of Pesticide Recidue in Indonesia's Commercial Tea using Chrmatography Gas Equipped Electrone Capture Detector}

\author{
Retno Yusiasih, Andreas, Dyah Styarini dan Y. Susanto Ridwan \\ Pusat Penelitian Kimia, Lembaga IImu Pengetahuan Indonesia (LIPI) \\ Komplek LIPI, Jl. Cistu - Sangkuriang, Bandung,40135 \\ E-mail: retnoyusiasih@yahoo.com
}

Diterima: 22 September 2014, Direvisi: 18 Desember 2014, Disetujui: 31 Desember 2014

\begin{abstract}
Abstrak
Teh yang dipertimbangkan sebagai minuman sehat, seharusnya bebas dari unsur beracun seperti pestisida. Daun teh mengandung berbagai senyawa yang sangat kompleks dimana kandungan residu pestisida harus di bawah Batas Maksimum Resdiu (BMR) yang diijinkan. Oleh karena itu analisis residu pestisida dalam teh merupakan tantangan tersendiri bagi laboratorium pengujian. Penelitian ini bertujuan untuk menentukan kandungan residu pestisida dalam teh komersial di Indonesia, khususnya Jawa Barat dengan metoda pengujian yang telah dikembangkan oleh Laboratorium Kimia Analitik dan Standar, Pusat Peneliitian Kimia - LIPI. Residu pestisida yang dianalisis adalah $\alpha$-endosulfan dan bifentrin. Instrument GC-ECD yang digunakan mempunyai kinerja sangat baik yang ditunjukkan dengan parameter verifikasi sangat memuaskan. Parameter verifikasi terdiri dari Instrumen detection limit (IDL) sebesar 0,034 dan 0,335 $\mathrm{ng} / \mathrm{g}$ untuk $\alpha$-endosulfan dan bifentrin, linieritas dengan nilai regresi $\left(r^{2}\right)$ sebesar 0,9995 pada konsentrasi $1,42-128 \mathrm{ng} / \mathrm{g}$ untuk $\alpha$-endosulfan dan 0,9980 pada konsentrasi $1,43-129 \mathrm{ng} / \mathrm{g}$ untuk bifentrin, presisi waktu tambat $\left(\mathrm{t}_{\mathrm{R}}\right.$ ) dan luas puncak (area) sebesar 0,026 dan $4,012 \%$ untuk $\alpha$-endosulfan serta $0,031 \%$ dan $4,95 \%$ untuk bifentrin. Metoda pengujian yang digunakan sangat baik yang ditunjukkan dengan parameter validasi sangat memuaskan yang terdiri dari akurasi sebesar $78 \%$ dan $90 \%$ dengan presisi sebesar $19,04 \%$ dan $18,93 \%$ untuk $\alpha$-endosulfan dan bifentrin. Kisaran konsentrasi yang dapat diterima dengan ketidakpastian pengukuran sebesar $\pm 20 \%-30 \%$ untuk $\alpha$-endosulfan dan bifentrin. Pada Internasional uji banding laboratoium, memberikan hasil memuaskan dengan nilai $|\mathrm{Z}| \leq 2$, baik untuk $\alpha$ endosulfan maupun bifentrin. Analisis residu pestisida dalam teh komersial untuk kedua senyawa tersebut, masih dibawah BMR yaitu $30 \mu \mathrm{g} / \mathrm{g}$ sehingga aman dikonsumsi.
\end{abstract}

Kata kunci : teh, pestisida, validasi metoda, GC-ECD.

\begin{abstract}
Tea is considered as a healthy beverage, should be free of toxic elements such as pesticides. Tea leaves contain various compounds that are highly complex and content of pesticide residues should be below Maximum Residu Limit (MRL). Therefore, the analysis of pesticide residues in tea is a challenge for laboratory testing. This study aims to determine the pesticide residues content in Indonesia's commercial tea, especially West Java with the testing method which was developed by Analytical Chemistry and Standard Laboratory, Research Center for Chemistry - LIPI. Residue pesticides analyzed were a-endosulfan and bifenthrin. GC-ECD instrument used has excellent performance with the verification parameters shown very satisfactory. Parameter verification consists of Instrument detection limit (IDL) of 0.034 and $0.335 \mathrm{ng} / \mathrm{g}$ for $\alpha$-endosulfan and bifenthrin, linearity with regression values $\left(r^{2}\right)$ of 0.9995 at concentrations of 1.42 to $128 \mathrm{ng} / \mathrm{g}$ for $\alpha$-endosulfan and 0.9980 at concentrations of 1.43$129 \mathrm{ng} / \mathrm{g}$ for bifenthrin, precision retention time $\left(t_{R}\right)$ and peak (area) of 0.026 and $4.012 \%$ for $\alpha$-endosulfan and 0.031 and $4.95 \%$ for bifenthrin. The testing method used is very good as indicated by the very satisfactory validation parameters consisting of an accuracy of $78 \%$ and $90 \%$ with a precision of $19.04 \%$ and $18.93 \%$ for $\alpha$ endosulfan and bifenthrin. Acceptable concentration range with a uncertainty measurement of $\pm 20 \%-30 \%$ for $\alpha$ endosulfan and bifenthrin. The international laboratory comparisons, gave satisfactory results with the value of $/ Z$ $1 \leq 2$, both for $\alpha$-endosulfan and bifenthrin. Analysis of pesticide residues in commercial tea of the two compounds was under MRL that is $30 \mu \mathrm{g} / \mathrm{g}$, so safe for consumed.
\end{abstract}

Keywords: tea, pesticides, methods validation, GC-ECD. 


\section{PENDAHULUAN}

Teh yang berasal dari daun Camellia sinensis (L.) disajikan dengan cara diseduh dengan air panas. Minuman tersebut sudah lama di kenal dan sampai saat ini masih populer karena mempunyai aroma dan flavor yang spesifik. Teh dipromosikan sebagai minuman sehat yang menguntungkan bagi manusia, karena mengandung antioksidan, antimikrobial, antikarsinogen dan anti-inflamasi sehingga banyak diterima oleh masyarakat luas. Sebanyak 2,5 juta ton produksi teh per tahun dihasilkan di dunia. Tergantung dari proses fermentasi daun teh segar, pada umumnya akan dihasilkan sebanyak $20 \%$ teh hijau dan $80 \%$ teh hitam. Sampel teh, mengandung berbagai komponen, termasuk di dalamnya adalah kandungan pigmen yang tinggi, alkanoid, kafein dan polifenol.

Untuk melidungi tanaman teh dari serangan hama dan juga untuk meningkatkan produksi teh, berbagai jenis pestisida diaplikasikan pada perkebunan teh. Residu pestisida yang masih tertinggal pada daun teh yang dipanen dan diproses hingga menjadi teh siap seduh inilah yang dikhawatirkan akan menimbulkan efek negatif bagi kesehatan konsumen, karena pestisida merupakan senyawa yang beracun. Untuk menghindari hal tersebut, beberapa peraturan terkait kandungan maksimum pestisida dalam teh telah dibuat di berbagai negara. Batas maksimum residu (BMR) yang diijinkan sangat rendah bahkan dalam tingkat runut. Untuk itu, pengembangan metoda yang sangat sensitif dan akurat untuk menentukan jumlah residu pestisida dalam teh menjadi sangat penting dan bernilai ekonomi tinggi.

Berbagai metode analisis residu pestisida dalam teh banyak dikembangkan, mengingat jenis senyawa pestisida yang diaplikasikan cukup beragam, serta matriks teh yang sangat kompleks sehingga cukup menyulitkan untuk analisis kuantitatif. Untuk diperoleh hasil analisis yang akurat, pemilihan pelarut pada proses ekstraksi menjadi sangat penting, karena ekstraksi adalah tahap awal yang sangat menentukan dalam proses analisis. Hal ini merupakan tantangan bagi laboratorium pengujian. Selain itu, tahap pemurnian juga akan memainkan peran yang penting, karena bila di dalam hasil ekstrak masih banyak senyawasenyawa matriks, akan menyulitkan saat pemisahan dalam kromatografi gas dan pada akhirnya akan menyulitkan kuantitasi senyawa target.
Dengan adanya metoda analisis residu pestisida dalam teh yang akurat dan kemudian dapat diaplikasikan untuk memonitoring keberadaan residu pestisida dalam teh yang beredar di pasaran, diharapkan dapat membantu meningkatkan kewaspadaan terhadap residu pestisida dalam teh yang dikonsumsi sehari-hari oleh masyarakat.

Tujuan penelitian ini adalah untuk mengevaluasi kadar residu pestisida dalam teh komersial yang beredar di pasar lokal di Indonesia, Jawa Barat khususnya. Metoda pengujian yang digunkan adalah modifikasi metoda yang di adopsi dari Direktorat Jenderal Tanaman Pangan. Oleh karena itu perlu dilakukan validasi metoda yang terdiri dari presisi, akurasi, perhitungan ketidakpastian pengukuran, dan keikiutsertaan dalam Internasional uji banding laboratorium agar diperoleh hasil analisis yang dapat diterima (reliable). Analisis residu pestisida dilakukan dengan menggunakan Kromatografi Gas (GC) yang dilengkapi dengan detektor penangkap elektron (ECD). Senyawa pestisida yang dianalisis adalah $\alpha$-endosulfan yang merupakan salah satu jenis pestisida golongan organoklorin dan bifentrin yang merupakan salah satu jenis pestisida golongan pyretroid.

\section{TINJAUAN PUSTAKA}

Seperti tanaman lainnya, tanaman teh bahkan sampai penyimpanan hasil panen dilindungi dari serangan hama dengan berbagai jenis pestisida. Pestisida golongan insektisida yang sering di gunakan untuk melindungi tanaman teh dari serangan hama adalah dicofol, ethion, endosulfan, chlorpyrifos, quinalpos, fenpropathin, propargite dan lain sebagainya. Pestisida golongan herbisida maupun fungisida lain yang sering digunakan adalah organoklorin, pyrentrin, pyretroid, carbendazin, carbamate, carbofuran dan acetamiprid.

Penggunaan jumlah pestisida meningkat agar produksi teh juga meningkat, karena kerusakan tanaman teh yang di akibatkan oleh berbagai jenis hama termasuk jamur dapat mengurangi hasil panen sekitar $7-10 \%$. Sehingga pestisida mempunyai peran dan kontribusi yang cukup dramatis untuk meningkatkan jumlah panen teh dari berbagai varietas, tanpa memperhatikan residu pestisida yang ditinggalkan dalam produk teh tersebut. Walaupun pestisida akan terdegradasi secara termal selama proses panen, penyimpanan, dan produksi, tetapi kandungan residu pestisida dalam teh perlu diketahui secara pasti apakah 
telah sesuai dengan BMR yang di perbolehkan sehingga dapat memenuhi persyaratan kualitas dan baku mutu pangan. Residu pestisida dalam teh lebih banyak dibanding tanaman yang lain walaupun digunakan dalam dosis yang sama. Hal ini disebabkan karena teh disemprot langsung dengan pestisida pada permukaan daun, dan proses panen dilakukan dalam selang beberapa hari setelah daun teh disemprot dengan pestisida. Daun teh segar diproses secara lansung untuk produksi tanpa dicuci terlebih dahulu. Dengan demikian, residu pestisida yang terdapat pada permukaan daun teh akan terserap selama proses fermentasi. Hal ini akan memberikan kontribusi bahan kimia berbahaya bagi konsumen. Karena itu, residu pestisida dalam teh dapat menimbulkan resiko terhadap kesehatan konsumen dan juga akan merugikan secara ekonomi.

Meningkatnya kandungan pestisida dalam teh telah mendapat perhatian serius dari masyarakat luas, karena residu pestisida yang bersifat racun akan masuk dalam rantai makanan yang dapat mengancam kesehatan. Walaupun efek kesehatan akibat terpapar pestisida sangat individual, tetapi banyak penelitian mengidentifikasi bahwa terpapar pestisida dapat menyebabkan kanker, mengganggu kerja pankreas dan sistem hormon. Oleh karena itu, pemerintah dan regulator terkait telah memberi tekanan kepada produsen dan distributor teh untuk menghasilkan dan menjual produk teh dengan kualitas yang baik sesuai dengan standar yang dipersyaratkan. Hal ini dilakukan tidak hanya untuk mengontrol kandungan residu pestisida dalam teh sebelum sampai kepada konsumen, akan tetapi juga untuk mengurangi jumlah penggunaan pestisida. Dengan demikian kesehatan konsumen akan terjamin. Batas toleransi penggunaan pestisida bagi berbagai negara pengekspor teh telah diatur oleh pemerintah. Namun demikian, masing-masing negara mempunyai batas toleransi yang sering kali berbeda. Hal ini mungkin disebabkan oleh iklim yang berbeda. European United (EU) telah mengeluarkan daftar dari 448 residu pestisida dalam teh, dengan BMR yang diperbolehkan antara 0,005 - 350 $\mathrm{mg} / \mathrm{kg}$.

Analisis adanya residu pestisidan dalam teh dilakukan sebagai Quality Control (QC) dan monitoring terhadap lingkungan sebagai jaminan perlidungan terhadap kesehatan bagi konsumen. Kandungan residu pestisida dalam teh yang sangat rendah, telah meningkatkan kesadaran internasional akan betapa pentingnya metoda analitik yang handal dalam merespon kandungan bahan kimia berbahaya dalam teh yang dapat digunakan untuk tujuan monitoring. Pengembangan metoda untuk analisis residu pestisida harus mempertimbangkan faktor waktu dan biaya tanpa mengurangi karasteristik kinerja yang relevan. Kromatografi gas adalah salah satu instrumen yang sangat sensitif untuk menentukan kandungan residu pestisida yang mempunyai sifat termal stabil, polaritas rendah dan volatil, seperti organophosporus, pyretroid dan organoklorin. Dengan spesifikasi tersebut, kromatografi gas secara luas di gunakan untuk memonitor keamanan teh terhadap kandungan residu pestisida. Demikian juga pemilihan detektor merupakan hal yang sangat penting. Sifat senyawa target yang akan dianalis harus diketahui dengan pasti sehingga dapat ditentukan detektor yang sesuai agar diperoleh hasil analisis yang akurat. Endosulfan dan bifentrin mempunyai rumus molekul masing masing $\mathrm{C}_{9} \mathrm{H}_{6} \mathrm{Cl}_{6} \mathrm{O}_{3} \mathrm{~S}$ dan $\mathrm{C}_{23} \mathrm{H}_{22} \mathrm{ClF}_{3} \mathrm{O}_{2}$. Adanya gugus khlorida yang dapat melepaskan elektron di dalam kedua senyawa tersebut sangat tepat untuk digunakan detektor penangkap elektron (ECD). Telah banyak metoda analitik digunakan untuk mengontrol tingkat keberadaan residu pestisida dalam komoditi teh. Tahap ektraksi, pemurnian, serta kondisi pemisahan di instrumen analitik yang digunakan, merupakan tahap yang paling krusial. Penentuan kuantitas kandungan residu pestisida secara akurat tidaklah mudah. Untuk memperoleh sistim pengukuran yang reliable, penggunaan peralatan analitik yang sangat sensitif dan terkalibrasi serta staff yang terlatih merupakan persyaratan yang harus dipenuhi oleh laboratorium terakreditasi ISO/IEC $17025: 2005$.

\section{METODE PENELITIAN}

Sampel teh yang berasal dari 7 (tujuh) merek dagang dengan Kode : I - VII diambil secara acak dari 3 (tiga) pasar lokal dengan Kode $1-3$ di Jawa Barat, Indonesia. Analisis residu pestisida meliputi tiga tahap yaitu ekstraksi, pemurnian dan analisis menggunakan Kromatografi Gas (GC) yang dilengkapai dengan detektor penangkap elektron (ECD). Ekstraksi dilakukan dengan merendam semalam pada temperatur ruang $5 \mathrm{gr}$ sampel teh dalam campuran aseton/diklorometan (50/50, v/v) sebanyak $50 \mathrm{ml}$. Fasa cair yang diperoleh di sentrifugasi dan dipisahkan dari endapannya. Filtrat yang diperoleh kemudian dievaporasi sampai hampir kering, kemudian dilarutkan dalam $n$-heksan. Pemurnian dilakukan dengan menggunakan kolom florisil dan dielusi dengan campuran $n$-heksan/dietileter (85/15, v/v). Eluat yang diperoleh diinjeksikan ke dalam GC-ECD 
sebanyak $2 \mu \mathrm{L}$. Kondisi optimum operasional GCECD adalah suhu injektor $250^{\circ} \mathrm{C}$, suhu detektor $300^{\circ} \mathrm{C}$, laju alir gas pembawa helium $(\mathrm{He}) 1$ $\mathrm{ml} / \mathrm{menit}$. Suhu awal kolom oven pada $120^{\circ} \mathrm{C}$ ditahan selama 1 menit, kemudian dinaikkan hingga mencapai $250^{\circ} \mathrm{C}$ dengan kecepatan kenaikan suhu $25^{\circ} \mathrm{C}$ per menit, setelah mencapai suhu $250^{\circ} \mathrm{C}$ ditahan selama 5 menit. Selanjutnya dinaikkan hingga mencapai $300^{\circ} \mathrm{C}$ dengan kecepatan kenaikan suhu $5^{\circ} \mathrm{C}$ per menit, kemudian ditahan selama 2 menit.

Adapun bahan - bahan yang digunakan dalam penelitian ini adalah pelarut seperti aseton, diklorometan, n-heksan, dietileter dan florisil diperoleh dari Merck dengan grade pa. Senyawa standar $\alpha$-endosulfan dan bifentrin masing - masing dengan kemurnian 99,5 \% dan 99\% diperoleh dari Chem. Service West Chester, PA USA. Dua jenis gas yang merupakan fasa gerak GC-ECD adalah Helium, Ultra High Purity (UHP) dan Nitrogen UHP sebagai make up gas. Sedangkan peralatan yang digunakan adalah instrumen analitik kromatografi gas (GC) HP6890 series yang dilengkapi dengan Electron Capture Detector (ECD). Kolom kapiler yang digunakan adalah jenis DB-5 dengan panjang 30 meter, diameter dalam $0,25 \mathrm{~mm}$ dan tebal film sebagai fasa diam adalah 0,25 $\mu \mathrm{m}$. Peralatan lain yang digunakan adalah neraca analitik terkalibrasi, rotary evaporator dan alat gelas lainnya.

\section{HASIL DAN PEMBAHASAN}

Kinerja dari instrumen yang digunakan untuk analisis senyawa pestisida organoklorin dan piretroid dalam teh perlu diketahui. Oleh karena itu, telah dilakukan verifikasi GC-ECD yang meliputi limit deteksi Instrumen (IDL), rentang kerja dan linieritas, serta presisi untuk waktu tambat $\left(t_{R}\right)$ dan luas puncak (area) dari senyawa target. Sesuai dengan ISO/IEC 17025, laboratorium harus melakukan validasi metoda apabila digunakan metoda yang dimodifikasi, termasuk di dalamnya menghitung estimasi ketidakpastian pengukuran (uncertainty) dan uji banding laboratorium (profeciency test).

\subsection{Verifikasi Instrumen GC - ECD}

Instrument of Detection Limit (IDL), adalah konsentrasi terendah senyawa target yang dapat dideteksi GC-ECD yaitu sebesar 0,034 dan 0,335 $\mathrm{ng} / \mathrm{g}$ beturut - turut untuk $\alpha$-endosulfan dan bifentrin, yang relatif sangat rendah yaitu $<1$ $\mathrm{ng} / \mathrm{g}$. Linieritas GC-ECD ditunjukkan dengan koefisien korelasi $\left(r^{2}\right)$. Dari percobaan ini, diperoleh nilai $r^{2}$ sebesar 0,9995 pada konsentrasi 1,42 - $128 \mathrm{ng} / \mathrm{g}$ untuk $\alpha$-endosulfan; dan 0,9980 pada konsentrasi 1,43- $129 \mathrm{ng} / \mathrm{g}$ untuk bifentrin. Sehingga secara keseluruhan dapat dikatakan bahwa linieritas GC - ECD terhadap kedua senyawa target sangat baik yang ditunjukkan dengan nilai $r^{2}$ mendekati 1 dengan konsentrasi antara 1,40 - $130 \mathrm{ng} / \mathrm{g}$. Presisi (kecermatan) GC-ECD ditentukan dengan menghitung Standar Deviasi Relatif (SDR, \%), baik untuk waktu tambat $\left(t_{R}\right)$ maupun luas puncak (area). Dari percobaan yang telah dilakukan, diperoleh kecermatan alat untuk $t_{R}$ dan area berturut-turut sebesar 0,026\% dan $4,023 \%$ untuk senyawa $\alpha$-endosulfan; serta 0,031\% dan 4,927\% untuk senyawa bifentrin. Dengan demikian dapat dikatakan bahwa untuk analisis kedua senyawa tersebut dengan menggunakan GC-ECD, mempunyai kecermatan yang cukup tinggi yang ditunjukkan dengan $S D R<0.03 \%$ untuk presisi $t_{R}$ dan $R S D$ $<5 \%$ untuk presisi area.

\subsection{Validasi Metoda}

Validasi metoda adalah proses karakterisasi kinerja metoda pengujian. Beberapa informasi karakteristik tersebut harus ditetapkan sebelum analisis sampel, sedangkan reprodusibilitas ditentukan kemudian sebagai Analitycal Quality Control (AQC). Penentuan presisi metoda dilakukan dengan cara analisis secara berulang pada kondisi optimum dengan ditunjukkan nilai SDR (\%) yang dapat diterima apabila mempunyai nilai lebih kecil dari Koefisien Variansi yang diformulasikan oleh Horwitz $\left(\mathrm{CV}_{\text {Horwitz }}\right)$. Salah satu cara untuk penentuan akurasi metoda adalah dengan menghitung perolehan kembali hasil analisis. Sejumlah standar yang telah diketahui konsentrasinya sebagai nilai sebenarnya, ditambahkan ke dalam sampel teh (spike), selanjutnya dianalisis secara kuantitatif dan dihitung konsentrasi sebagai nilai hasil analisis yang ditemukan. Dari hasil analisis, akurasi yang ditunjukan dengan perolehan kembali diketahui bahwa akurasi metoda relatif baik yang ditunjukkan dengan nilai perolehan kembali berturut - turut sebesar 78\% untuk $\alpha$ endosulfan dan $90 \%$ untuk bifentrin, dengan presisi yang ditunjukkan nilai SDR sebesar $19,04 \%$ dan 18,93\% dimana nilai SDR tersebut masih di bawah $\mathrm{CV}_{\text {Horwitz yaitu } 20,11 \% \text { dan }}$ 19,97\%. Tingkat keberterimaan perolehan kembali (\% akurasi), sangat relatif tergantung pada konsentrasi kandungan senyawa target yang dianalisis. Menurut Ralf (2000), semakin kecil konsentrasi analit, akan semakin besar \% akurasi yang dapat diterima, seperti terlihat dalan Tabel 1. 
Tabel 1 Rentang persen akurasi (recovery) terhadap konsentrasi senyawa target.

\begin{tabular}{lc}
\hline \multicolumn{1}{c}{ Konsentrasi } & $\begin{array}{c}\text { Rentang persen akurasi } \\
\text { (persen, recovery) }\end{array}$ \\
\hline$\leq 1 \mu \mathrm{g} / \mathrm{kg}$ & $50-120$ \\
$>1 \mu \mathrm{g} / \mathrm{kg} \leq 0.01 \mathrm{mg} / \mathrm{kg}$ & $60-120$ \\
$>0.01 \mathrm{mg} / \mathrm{kg} \leq 0.1 \mathrm{mg} / \mathrm{kg}$ & $70-120$ \\
$>0.1 \mathrm{mg} / \mathrm{kg} \leq 1 \mathrm{mg} / \mathrm{kg}$ & $70-110$ \\
$>1 \mathrm{mg} / \mathrm{kg}$ & $70-110$ \\
\hline
\end{tabular}

\subsection{Estimasi Ketidakpastian Pengukuran}

Perhitungan estimasi ketidakpastian pengujian (Uncertainty) dilakukan dengan menggunakan pendekatan bottom-up untuk menghitung satu per satu semua aspek yang dapat memberikan sumbangan kesalahan pada saat pengukuran atau pengujian dilakukan. Nilai estimasi ketidakpastian dapat digunakan untuk mengetahui rentang konsentrasi yang dapat diterima. Adapun besarnya nilai ketidakpastian metoda pengujian yang diperoleh dalam penelitian ini adalah sekitar $\pm 20 \%-30 \%$ untuk senyawa target yang dianalisis yaitu $\alpha$ endosulfan dan bifentrin.

\subsection{Internasional Uji Banding Laboratorium di} Tingkat Regional.

Asia Pasific Metrology Programme (APMP) pernah menyelenggarakan uji banding laboratorium tingkat regional Asia Pasifik yang diikuti oleh 42 laboratrium pengujian dari 11 negara yaitu Australia, China, India, Indonesia, Laos, Malaysia, Mongolia, New Zealand, Philipina, Sri Lanka dan Thailand. Kinerja dari laboratorium peserta uji banding tersebut dievaluasi berdasarkan nilai $Z$-score. Dengan ketentuan bahwa nilai $Z$-score mutlak $|Z| \leq 2$ mempunyai hasil pengujian memuaskan, $2 \leq|\mathrm{Z}|$ $\leq 3$ peringatan dan $|Z| \geq 3$ tidak memuaskan. Laboratorium Kimia Analitik dan Standar, Pusat Penelitian Kimia - LIPI, Indonesia, memberikan hasil pengujian memuaskan yang di tunjukkan dengan nilai $|Z| \leq 2$ baik untuk $\alpha$-endosulfan maupun bifentrin. Selanjutnya, dengan instrumen GC-ECD dan metoda pengujian yang telah ditentukan kinerjanya, digunakan untuk analisis kedua senyawa tersebut dalam teh komersial yang beredar di pasar lokal di Indonesia, khususnya daerah Jawa Barat untuk membuktikan bahwa instrumen yang digunakan dan metoda pengujian yang dikembangkan dapat diaplikasikan.

\subsection{Analisis Residu Pestisida dalam Teh Komersial di Indonesia}

Beberapa sampel teh komersial yang diambil di beberapa pasar lokal dianalisis menggunakan instrumen GC-ECD yang telah diverifikasi dan metoda analisis yang telah divalidasi. Hasil analisis yang diperoleh tercantum dalam Tabel 2 yang menunjukkan kandungan senyawa $\alpha$ endosulfan antara <MDL s.d 20,16 ng/g (ppb) dan senyawa bifenthrin antara $<M D L$ s.d 7,41 $\mathrm{ng} / \mathrm{g}$. BMR untuk $\alpha$-endosulfan sebesar $30 \mu \mathrm{g} / \mathrm{g}$ (ppm) dan untuk bifentrin $0,1-25 \mu \mathrm{g} / \mathrm{g}(\mathrm{ppm})$. Hal menunjukkan bahwa metoda analisis yang diaplikasikan dalam teh komersial terbukti mudah digunakan dan sangat sensitif.

Sesuai dengan Peraturan Pemerintah Republik Indonesia No. 6 Tahun 1995 tentang Perlindungan Tanaman yaitu BMR kandungan endosulfan dalam teh yang diperbolehkan

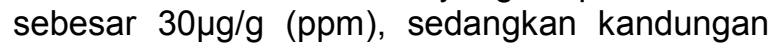
bifentrin dalam matrik teh yang diperbolehkan belum diatur, namun di beberapa negara lain telah menetapkan BMR untuk bifentrin dalam matriks teh berkisar antara 0,1 hingga $25 \mu \mathrm{g} / \mathrm{g}$ (ppm). Dengan demikian kandungan pestisida senyawa $\alpha$-endosulfan dan bifentrin dalam teh komersial yang beredar di Jawa Barat, Indonesia di bawah BMR sehingga aman dikonsumsi.

Tabel 2 Kandungan $\alpha$-endosulfan dan bifentrin dalam teh komersial di Jawa Barat - Indonesia.

\begin{tabular}{ccc}
\hline Kode $^{\star *}$ & \multicolumn{2}{c}{ Kandungan Senyawa Dalam Teh (ng/g) } \\
\cline { 2 - 3 } Sampel & $\alpha$-endosulfan & bifenthrin $^{*}$ \\
\hline $\mathrm{I}-1$ & 4.87 & 4.29 \\
$\mathrm{I}-2$ & 9.57 & $<\mathrm{MDL}$ \\
$\mathrm{I}-3$ & 17.04 & 2.19 \\
\hline $\mathrm{II}-1$ & $<\mathrm{MDL}$ & 1.38 \\
$\mathrm{II}-2$ & $<\mathrm{MDL}$ & 1.49 \\
$\mathrm{II}-3$ & $<\mathrm{MDL}$ & 1.41 \\
\hline
\end{tabular}




\begin{tabular}{|c|c|c|}
\hline \multirow{2}{*}{$\begin{array}{l}\text { Kode } \\
\text { Sampel }\end{array}$} & \multicolumn{2}{|c|}{ Kandungan Senyawa Dalam Teh $(\mathrm{ng} / \mathrm{g})$} \\
\hline & $\alpha$-endosulfan ${ }^{\star}$ & bifenthrin $^{*}$ \\
\hline III -1 & $<\mathrm{MDL}$ & 4.26 \\
\hline III -2 & $<\mathrm{MDL}$ & 7.41 \\
\hline III -3 & $<\mathrm{MDL}$ & 3.47 \\
\hline IV -1 & $<\mathrm{MDL}$ & $<\mathrm{MDL}$ \\
\hline IV -2 & 3.87 & $<M D L$ \\
\hline IV -3 & 11.35 & 1.72 \\
\hline$V-1$ & $<M D L$ & 1.42 \\
\hline$v-2$ & 4.48 & 5.55 \\
\hline$v-3$ & 1.53 & 4.64 \\
\hline $\mathrm{VI}-1$ & 5.20 & 1.51 \\
\hline $\mathrm{VI}-2$ & 18.12 & 2.08 \\
\hline $\mathrm{VI}-3$ & 9.76 & 1.14 \\
\hline $\mathrm{VII}-1$ & 2.48 & $<\mathrm{MDL}$ \\
\hline $\mathrm{VII}-2$ & 8.93 & $<\mathrm{MDL}$ \\
\hline VII -3 & 20.16 & $<\mathrm{MDL}$ \\
\hline
\end{tabular}

${ }^{*}$ BMR $\alpha$-endosulfan : $30 \mu \mathrm{g} / \mathrm{g}(\mathrm{ppm})$ dan bifentrin : 0,1 - $25 \mu \mathrm{g} / \mathrm{g}(\mathrm{ppm}), \mathrm{MDL}=0,5 \mathrm{ng} / \mathrm{g}(\mathrm{ppb})$

${ }^{* *} I-$ VII : kode merek dagang Teh, $1-3$ : kode Pasar lokal

\section{KESIMPULAN}

Teh yang dipertimbangkan sebagai minuman sehat, seharusnya tidak mengandung bahan kimia berbahaya yang besifat toksik seperti pestisida. Kompleksnya matriks dalam teh serta kandungan residu pestisida yang mungkin terdapat dalam produk teh dalam level sangat rendah (trace level), maka analisis residu pestisida dalam teh merupakan tantangan tersendiri bagi laboratorium pengujian.

Instrumen analitik GC-ECD yang digunakan untuk analisis residu perstisida $\alpha$ endosulfan dan bifentrin dalam teh mempunyai kinerja yang sangat baik yang ditunjukkan dengan parameter verifikasi memuaskan yang terdiri dari Instrumen Detection Limit (IDL), linieritas, dan presisi pada kondisi optimum pemisahan kedua senyawa target tersebut. Demikian juga metoda pengujian yang digunakan sangat baik yang ditunjukkan dengan parameter validasi memuaskan yang terdiri dari perolehan kembali (akurasi) dan presisi, serta ketidakpastian pengukuran dan uji banding laboratoium yang diikuti secara internasional. Hasil yang sangat baik pada verifikasi instrumen dan validasi metoda menunjukkan strategi yang mudah diaplikasikan, andal dan dapat diterima.

Analisis residu pestisida dalam teh komersial dengan GC-ECD dengan metoda analisis yang telah ditentukan kinerjanya, memberikan informasi bahwa teh komersial yang beredar di pasar lokal, khususnya Jawa Barat Indonesia, aman dikonsumsi.

\section{UCAPAN TERIMAKASIH}

Terima kasih diucapkan kepada Pusat Penelitian Kimia, Lembaga IImu Pengetahuan Indonesia untuk memberikan dukungan dalam peneitian ini. Demikian juga terima kasih setinggi-tingginya untuk Ibu Sayekti Eka atas bantuannya selama pengujian di Laboratorium.

\section{DAFTAR PUSTAKA}

Aybar-Muñz J., Ferna'ndez-Gonza'lez, E., Garci'a-Ayuso, L.E., Gonza'lez-Casado, A. and Cuadros-Rodri'guez, L. (2005). Chromatographia. 61, 505-513.

Caihong Lu, Xingang Liu, Fengshou Dong, Jun $\mathrm{Xu}$, Wencheng Song, Changpeng Zhang, Yuanbo Li, Yongquan Zheng. (2010). Analytica Chimica Acta. 678, 56-62.

Della W.M. Sin, Pui-kwan Chan, Samuel T.C. Cheung, Yee-Lok Wong, Siu-kay Wong, Chuen-shing Mok, Yiu-chung Wong. (2012). Analytica Chimica Acta. 721, 110114.

Disni Dayarathna, Champika Thirimanna, Azeez Mubarak, Lindsey Mackay, Jill Rogerson, Hua Tang, Jie Feng, Della W.M. Sin, Yiuchung Wong. (2013). Food Research International. 53, 931-937.

EU Reference Laboratories for Residues of Pesticides. (2007). Document N SANCO/2007/3131: Method Validation and Quality Control Procedures for Pesticides Recidues Aanalysis in Food and Feed. 
Hong-Ping Li, Gwo-Chen Li and Jen-Fon Jen. (2004). Journal of the Chinese Chemical Society. 51 ,

$$
\text { 531-542. }
$$

Maryam Amirahmadi, Shahram Shoeibi, Mehdi Abdollahi, Hossein Rastegar, Roya Khosrokhavar and Morteza Pirali Hamedani. (2013). Iranian Journal of Environmental Health Sciences and Engineering. 10:9, 1-6.

Nobuo Ochiai, Kikuo Sasamoto, Hirooki Kanda, Takashi Yamagami, Frank David, Pat Sandra. (2004). Multi-Residue Method for Determination of 85 Pesticides in Vegetables, Fruits and Green Tea by Stir Bar Sorptive Extraction and Thermal Desorption GC-MS. AN/2004/04, 1-8.

Ralf Hanel, Johannes Siebers and Karen Howard. (2000). EU Guidance Documen on Resiude Analytical Methods, dalam Principles and Practices of Method Validation. A.Faigelj and A. Ambrus, The Royal Society of Chemistry.

Schurek, J., Portol'es, T., Hajslova, J., Riddellova, K., Herna'ndez, F. (2008) Analytica Chimica Acta. 611, 163-172.
Subbiah Seenivasan dan Narayanan Nair Muraleedharan. (2011). Environ Monit Assess. 176, 365-371.

Tomas Cajka, Chris Sandy, Veronika Bachanova, Lucie Drabova, Kamila Kalachova, Jana Pulkrabova, Jana Hajslova. (2012). Analytica Chimica Acta. 743, 51-60.

Xin Li, Zhaowei Zhang, Peiwu Li, Qi Zhang, Wen Zhang, Xiaoxia Ding. (2013). Food Research International. 53, 649-658.

Xue Liu, Wenbi Guan, Xianghong Hao, Xiaoli Wu, Yongqiang Ma, Canping Pan. (2014). Chromatographia. 77, 31-37.

Xiaoling Cheng, Hongyuan Yan, Xiaoling Wang, Ning Sun, Xiaoqiang Qiao. (2014). Food Chemistry, 162, 104-109.

Zhiqiang Huang, Yongjun Li, Bo Chen, Shouzhuo Yao. (2007). Journal of Chromatography B, 853, 154-162.

Zhiqiang Huang, Ying Zhang, Libing Wang, Li Ding, Meilin Wang, Hongfei Yan, Yongjun Li, Shaohua Zhu. (2009). J. Sep. Sci., 32, 1294 - 1301. 
